\title{
Observing the process of mathematics teacher change-part 1
}

\author{
David Reid • Vicki Zack
}

Published online: 26 August 2010

(C) Springer Science+Business Media B.V. 2010

\section{Keywords Observing - Change}

Keeping in mind that "everything said is said by an observer" (Maturana 1987), we would like to preface our observations on the articles in this issue with some background on ourselves as observers.

We met by chance in 1994 (at PME 18, the 18th conference of the International Group for the Psychology of Mathematics Education, in Lisbon) and immediately felt that there were points of connection. From 1994 to 2001, we collaborated on Vicki's ongoing research in her classroom, sharing our different perspectives on the children's mathematical activities, developing lessons, and materials together, delving deeper into areas which have puzzled us and piqued our interest, and writing about our work together (Reid 2002a, b; Reid and Zack 2009; Zack 2006; Zack and Reid 2003, 2004). Our collaboration is unusual in that we began our collaboration without having a prior connection as, for example, a professor and a graduate student, or a researcher and a research participant.

From 1989 to 2001, Vicki taught full-time at the fifth-grade level (10-11 year olds) and researched the children's work in the areas of mathematics (problem solving) and literature. Her interest in their work in non-routine problem solving led her to be curious about her students' developing algebraic thinking and later to a focus on proof and argumentation, partly as a result of working with David, whose research focuses on proof.

David first became involved in teacher education in 1992 while completing his doctorate. He has continued to work primarily with prospective teachers, but also with practising teachers pursuing Master's studies, ever since. His focus gradually shifted from secondary school level to elementary school level, partly as a result of what he learned through working with Vicki.

We came to work on this special issue as a result of our own collaboration between an elementary school teacher and a university teacher educator, in which we have had many

D. Reid (西)

Acadia University, Wolfville, Canada

e-mail: david.reid@acadiau.ca

V. Zack

St. George's School, 5822 Einstein Ave., Montreal, Quebec H4W 2Y6, Canada 
occasions to reflect on our own growth as teachers and teacher educators in the collaboration. The topics of teacher research, teacher change, and the working relationships between teams consisting of teachers (in elementary and secondary schools) and others such as academics working at the university level have all been of import and interest to us. We have been involved in the research forums, discussion groups, and working sessions at PME, where issues related to teachers as researchers, teachers working alongside university academics, and teacher change with specific relevance to teachers beginning their careers have been explored. We have been intrigued by the diversity of perspectives evident there, both in the theoretical frameworks used in studies and in the moral and ethical attitudes concerning the power relations between co-researchers.

This diversity is reflected in the articles included in this issue. Even at the level of the description of the process of change, there are notable differences in the pace of change and the balance between explicit goals and serendipitous change. Change is often seen as a slow process, and most of the articles in this issue and the next describe processes that occurred over extended periods of time. Hunter, for example, documents a "gradual and often circuitous, and challenging journey of change." However, Liljedahl, through his interpretation, points out that changes can be quick but still deeply significant. The process of change can sometimes be driven by an explicit goal as in the articles by Hunter in which a shift to enquiry-oriented teaching was the goal and Boylan in which the Head Teacher, Anne, had chosen to work with Clive because of his resistance to change. At the same time, change can happen fortuitously. Even in cases where the teacher did not come to the process "looking for answers" (as in Liljedahl's description of Mitchell) or where the group working with a teacher had no predetermined outcomes (as in the group described by Muñoz-Catalán, Carrillo, and Climent) changes occur. A key element in these change processes, which is paralleled in many cases by the changes described in the learning contexts of the teachers' students, is the allowing for time, space, and flexibility (Boylan speaks of fluidity and spaciousness).

Two issues strike us in reading over the four assembled articles. One is the importance of emotional engagement to the process of change. The other is the vulnerability that occurs as part of change and how this is addressed from different perspectives.

The call for articles emphasised that change occurs from within: "I cannot change others, but I can work at changing myself" (Mason 1994, p. 177). Hence, the articles in this special issue focus on opportunities for teachers to change themselves. However, change does not occur for its own sake. Change must be motivated by some need, to adapt, or engage, or reject. There must be an emotional engagement in the process of change. And the way one changes is guided by emotions, as is any decision-making process (Damasio 1994). It is therefore interesting to look at how emotions have played a part in the process of teacher change described in the articles.

In several articles, teachers are described as being enthusiastic or excited by the process of change they were engaged in, often in contrast with other professional development activities. In Boylan's article, Clive notes that he is not excited about professional development in general, but he is enthusiastic about the work he did with Anna, his Head Teacher, in the project described. In Hunter's article, we see Moana's excitement, seeing for herself what the children can do, being amazed by those who exceed the (low) expectations she had.

Such positive experiences are welcome in their own right, but also important in suggesting the lasting impact of the changes that occurred. Emotionally charged events are more memorable and more likely (according to Damasio) to guide future decision-making. Boylan's article includes a striking illustration of how emotions and memory are linked. 
Clive recollects being set a task during a professional day long ago and how exciting the experience was. Even though the event occurred over 20 years ago, he can still recall the essence of the problem and also how involved everyone was with solving the problem.

Negative emotions can also be important, as a motivator for change and as a guide. In Liljedahl's article, Mary is dissatisfied by her teaching of mathematics, which motivates her to become involved in Master's studies as a way to change. And Karen reacts against the educational system as a whole, which she sees as making it impossible for students to succeed, but then is guided by this to explore ways to make changes to her own teaching to ensure that her students would be more successful.

Any change, even a welcome one, involves stress, as prior assumptions no longer apply. Unexpected or unwelcome changes can be traumatic. A time of change is a time of vulnerability, analogous to the moulting of a lobster, when it must give up its hard exoskeleton that protects it in order to grow. It takes a month to grow a new one and during this time the lobster increases in size by about $20 \%$, but must hide among rocks for protection.

Not all teacher change involves the level of vulnerability that lobsters experience. We (Vicki and David) have reflected together on our own changes as teachers supported by each other, and we do not recall any feelings of vulnerability, in spite of our different mathematical backgrounds, teaching experiences, and theoretical frameworks. In contrast, some of the processes of change described in this special issue involve situations of vulnerability. Muñoz-Catalán, Carrillo, and Climent note the importance of the trust between Julia, an inexperienced teacher, and Inés, who was much more experienced. This trust allowed Inés to ask "hard questions" (Jaworski 1998), which brought to light the ways in which Julia's personal theories influenced her teaching, an approach to change that must have left Julia feeling exposed. Without the protection afforded by her trust in Inés, she might have been unable to continue working with her due to this vulnerability.

Hunter comments on the need to establish trust with Moana, who was not confident about herself as a mathematician and whose recent professional development experiences had led her to feel a dissonance between her beliefs about mathematics teaching and the goals of a "top down" national programme to guide teachers to adopt a learner-centred approach to teaching. By taking a more collaborative approach, Hunter was able to work with Moana through extensive changes to Moana's teaching.

Boylan describes the collaboration between Anna and Clive, in which Clive commented on not feeling threatened, indicating awareness that feelings of vulnerability could easily have occurred as he and Anna looked together at his teaching. A key point in this situation seems to be Anna's focus on the lessons she observed, rather than on Clive as a teacher. In spite of her initial choice to work with Clive, precisely because she saw him as resistant to change, she did not set out to change him, but rather to look with him at the lessons he taught.

Anna's experience working with Clive illustrates another important thread that runs though the articles in this special issue: that of teacher-educator change. This is evident also in the articles by Hunter and Muñoz-Catalán, Carrillo, and Climent. Boylan notes that Anna learned from her experience with Clive that a collaborative and respectful approach to working with the teachers in her department is likely to lead to the goals she has for them all, more so than a more leadership-focused approach. Hunter learned from the experience of watching Moana and her students build on their shared culture to make sense of mathematics, an experience which taught Hunter that the norms of mathematics can be embedded in wider cultural contexts in many ways. Finally, Muñoz-Catalán, Carrillo, and Climent comment that working with Julia taught them that seeming inconsistencies in 
teachers' beliefs might reflect more about the observers than the teachers. With the noticing paradigm used by Liljedahl, we are of necessity seeing through the observer's awarenesses, whether we find those views warranted or not.

These issues, of the nature of the process of change, the importance of emotional engagement to the process of change, and the vulnerability that occurs as part of change, are not unique to mathematics teacher change. In our introductory editorial to the second part of this special issue, we will turn to elements of the process of teacher change that are related to the teaching and learning of mathematics specifically.

\section{References}

Damasio, A. (1994). Descartes' error: Emotion, reason, and the human brain. New York: Avon Books/G. P. Putnam's Sons.

Jaworski, B. (1998). Mathematics teacher research: Process, practice and the development of teaching. Journal of Mathematics Teacher Education, 1(1), 3-31.

Mason, J. (1994). Researching from the inside in mathematics education: Locating an I-you relationship. In J. P. da Ponte \& J. F. Matos (Eds.), Proceedings of the eighteenth conference of the international group for the Psychology of Mathematics Education (pp. 176-194). Lisbon, Portugal: University of Lisbon.

Maturana, H. R. (1987). Everything said is said by an observer. In W. Thompson (Ed.), Gaia: A way of knowing (pp. 65-82). Hudson, NY: Lindisfarne Press.

Reid, D. A. (2002a). Elements in accepting an explanation. Journal of Mathematical Behavior, 20(4), $527-547$.

Reid, D. A. (2002b). Conjectures and refutations in grade 5 mathematics. Journal for Research in Mathematics Education, 33(1), 5-29.

Reid, D., \& Zack, V. (2009). Aspects of teaching proving in upper elementary school. In D. Stylianou, M. Blanton, \& E. Knuth (Eds.), Teaching and learning proof across the grades. New York: Routledge.

Zack, V. (2006). What's a literature person like you doing, teaching and researching in elementary level mathematics? In C. Langrall (Ed.), Teachers engaged in research: Inquiry into mathematics classrooms, Grades 3-5 (pp. 201-224) Series Editor: D. Mewborn. Reston, VA: National Council of Teachers of Mathematics (NCTM), and Greenwich, CT: Information Age Publishing.

Zack, V., \& Reid, D. A. (2003). Good-enough understanding: Theorizing about the learning of complex ideas (Part 1). For the Learning of Mathematics, 23(3), 43-50.

Zack, V., \& Reid, D. A. (2004). Good-enough understanding: Theorizing about the learning of complex ideas (Part 2). For the Learning of Mathematics, 24(1), 25-28. 